\title{
BMJ Open Secondhand smoke exposure for different education levels: findings from a large, nationally representative survey in Turkey
}

\author{
Ömer Alkan (D) , Şeyda Ünver (D)
}

To cite: Alkan 0̈, Ünver Ş. Secondhand smoke exposure for different education levels: findings from a large, nationally representative survey in Turkey. BMJ Open 2022;12:e057360. doi:10.1136/ bmjopen-2021-057360

- Prepublication history and additional supplemental material for this paper are available online. To view these files, please visit the journal online (http://dx.doi.org/10.1136/ bmjopen-2021-057360).

Received 13 September 2021 Accepted 28 January 2022
Check for updates

(C) Author(s) (or their employer(s)) 2022. Re-use permitted under CC BY-NC. No commercial re-use. See rights and permissions. Published by BMJ.

Department of Econometrics, Faculty of Economics and Administrative Sciences, Ataturk University, Erzurum, Turkey

Correspondence to

Dr Ömer Alkan;

oalkan@atauni.edu.tr

\section{ABSTRACT}

Objectives The aim of this study is to determine the factors that influence individuals' exposure to tobacco smoke in Turkey according to their education level. Design Secondary data analysis.

Participants Altogether, 17084 individuals aged 15 and over were included in this study.

Settings Data set of the Turkey Health Survey in 2019. Methods Binary logistic regression analysis was used to determine the factors associated with individuals' exposure to tobacco smoke.

Primary and secondary outcome measures The variables age, gender, marital status, general health status, employment status, receipt of psychosocial support and tobacco use were found to be correlated with exposure to tobacco smoke.

Results The study determined that individuals who are illiterate/unschooled were exposed to tobacco smoke at a rate of $32.61 \%$, primary school graduates at a rate of $34.32 \%$, primary education graduates at a rate of $41.75 \%$, high school graduates at a rate of $41.04 \%$ and university graduates at a rate of $40.34 \%$

Conclusion As a result of the study, it is emphasised that men, young individuals, individuals with moderate and very good general health status, those who use tobacco, those who are unemployed and those who receive psychosocial support should be targeted. In addition, appropriate strategies for reducing secondhand smoke (SHS) exposure should be developed, taking into account public health strategies for increasing awareness of the adverse health effects of SHS exposure and the determinants of tobacco exposure according to the study.

\section{INTRODUCTION}

Today, public health is regarded as one of the most important indicators of a person's quality of life. Especially in recent years, public health has risen to prominence as a priority issue in all countries. ${ }^{1}$ Tobacco use, a global problem, is the leading preventable cause of death worldwide, with 6 million people dying each year due to tobacco use. ${ }^{2}$ Tobacco use has a harmful impact on not only smokers, but also on those exposed to secondhand smoke (SHS). ${ }^{3}$
Strengths and limitations of this study

In this study was used data from a nationally representative sample in Turkey.

- Binary logistic regression was conducted to determine the risk factors.

- Survey statistics in Stata V.15 were used to account for the complex sampling design and weights.

- This study used secondary data.

- The data for this study was collected through a selfreport survey, which may have resulted in reporting bias.

SHS is a mixture of side stream smoke released into the air by a lit tobacco product (cigarette, pipe or cigar) and mainstream smoke that is breathed back into the air by an active smoker. ${ }^{4}$ SHS contains over 7000 chemicals, only about 70 of which are known. ${ }^{5}$ Indoor SHS concentrations are dependents on the amount of tobacco smoked over time, the size of the room, the ventilation rate and other processes that can remove contaminants. ${ }^{6}$

Exposure to SHS causes significant health problems that endanger human health worldwide. Exposure to SHS is the third leading preventable cause of death worldwide. ${ }^{7}$ Chronic exposure to SHS is at least $80 \%-90 \%$ as harmful as chronic active smoking on an average. ${ }^{8}$ Each year, over 880000 people die as a result of exposure to SHS. ${ }^{9}$ Individuals exposed to SHS have a $20 \%-30 \%$ increased risk of in cardiovascular disease compared with those who are not exposed at all. ${ }^{10}$ Moreover, a similar increase in lung cancer was reported among individuals exposed to SHS compared with those who were not. ${ }^{3}$ Children are also affected by SHS exposure. Children exposed to SHS are at an increased risk of developing acute respiratory infections, auditory dysfunction and exacerbation of asthma. ${ }^{11} 12$ Therefore, exposure to SHS not 
only causes serious illness, but also imposes an economic and social burden. ${ }^{13}$

There is significant evidence that comprehensive smoke-free policies in public spaces are associated with lower tobacco use and SHS, resulting in reduced negative health implications. ${ }^{14-16}$ Controlling the prevalence of tobacco products and SHS is a significant global public health challenge. Comprehensive smoke-free legislation is required by Article 8 of the WHO's Framework Convention on Tobacco Control (FCTC) to eliminate tobacco use in all indoor public spaces, including workplaces. ${ }^{17}$ In 2007, the FCTC's Article 8 was revised. Parties to the FCTC have recommended that smoking be prohibited outdoors or in semi-open areas where appropriate, based on findings of potential health hazards. ${ }^{14}$

As of the end of 2017, 181 countries have signed the WHO's FCTC. ${ }^{18}$ However, progress in the fight against SHS varies greatly across countries. Less developed countries appear to benefit less from the fight against SHS. ${ }^{19}$ This could be due to the fact that these countries are new members of the FCTC. Furthermore, in terms of compliance with the smoking ban, the execution of agreed smoking prohibitions differs substantially between countries. Failure at the political economy level, a lack of government resources to implement laws and a lack of political will to protect public health all contribute to this. ${ }^{20}$ As a result, the level of enforcement and compliance is regarded as at least as crucial as the implementation of smoke-free policies, particularly in less developed countries. ${ }^{19}$

Since ratifying the FCTC in 2008, the Russian government has significantly enhanced its policies addressing smoke-free environments. It prohibits smoking in closed workplaces, closed public spaces, public transportation and some open locations (beaches, playgrounds, public building entrances and public transportation). ${ }^{18}$ Thailand passed partial smoke-free legislation in 1992, prohibiting smoking in public locations where such restrictions could be effectively enforced, such as hospitals, schools and air-conditioned workplaces. ${ }^{21}$ Ghana, one of the first nations to ratify the FCTC in 2004, prohibited smoking in any closed portion of a workplace or any other public place that was not designated. ${ }^{22} 23$ Chile implemented complete nationwide smoke-free legislation in 2013. This legislation prohibits smoking in all closed and semiclosed spaces of all workplaces and public locations, including the accommodation sector. ${ }^{24}$ In Brazil, the use of cigarettes (and other smoking products derived from tobacco) was banned in all public areas save areas designated for smoking exclusively, segregated and ventilated, in $1996 .{ }^{25}$ In 2005, Spain ratified the FCTC. Smoking is forbidden in all closed public spaces, workplaces and public transportation vehicles. ${ }^{26}$ Peru signed the FCTC in 2004. Smoking is prohibited in closed public and private buildings (bars, restaurants, movie theatres and government buildings), as well as on public transportation. ${ }^{27}$ In Australia, smoking is prohibited in closed public places under the 2003 Smoke-Free Public Places Act. ${ }^{28}$ In 2004,
Toronto and its neighbouring municipalities prohibited smoking indoors, including bars and casinos. In 2006, the Province of Ontario enacted a similar Smoke-Free Ontario Act. ${ }^{29}$

There are studies examining the effect of smoking bans in public areas on exposure to SHS. Air quality measurements in bars and cafes before and after smoke-free workplace laws revealed considerable post-legal decreases in fine particle air pollution. Furthermore, it has been discovered that reductions in SHS exposure as a result of smoke-free policies improve respiratory health among bar and cafe workers. ${ }^{30}$ A study conducted in Spain, which ratified the FCTC in 2005, discovered that, beginning in January 2006, a comprehensive ban on outdoor smoking in workplaces and a partial ban in restaurants were enforced, resulting in a reduction in workplace exposure to SHS from $40 \%$ to $9.0 \% .{ }^{31}$ In a study conducted in Mexico, which approved the FCTC in 2005, non-smoking spaces were established in public places and workplaces as part of the 2008 smoking ban. The study found that SHS exposure in closed workplaces dropped considerably compared with the previous month. ${ }^{32}$ According to a study conducted in India, which approved the FCTC in 2005, despite the smoking prohibition in public places, $36 \%$ of the restaurants are still not smoke-free, with hookah restaurants providing the largest exposure to tobacco smoke. ${ }^{33}$

There are additional studies examining the impact of smoke-free policies on tobacco usage prevalence. According to a study conducted in Norway, which approved the FCTC in 2005, there was a $6.8 \%$ decline in smoking among employees in the workplace after a smoking ban was implemented in indoor areas in June $2004 .{ }^{34}$ In a study conducted in Canada, which approved the FCTC in 2005, it was discovered that after the introduction of a comprehensive smoking prohibition policy in 2004, the prevalence of tobacco usage declined from $24.1 \%$ in 2003 to $18.2 \%$ in $2005 .{ }^{35}$ According to a study conducted in Italy, which approved the FCTC in 2008, the prevalence of tobacco use among all adults decreased by $7.3 \%$ before and after the approval of the comprehensive smoke-free law and the implementation of the no-smoking policy in public places. ${ }^{36}$ According to a study conducted in Spain, which approved the FCTC in 2005 , the number of smokers decreased by $2.3 \%$ after the smoking ban legislation was implemented in public places and workplaces. ${ }^{37}$ According to a study conducted in Ireland, which approved the FCTC in 2006, there was a $4.7 \%$ decline in smoking among bar staff after the public smoking ban compared with the pre-ban period. ${ }^{38}$

Turkey ratified the FCTC in $2004 .^{39}$ In order to establish a smoke-free Turkey and protect passive smokers, on 19 May 2008, the goal of the 'Smoke-Free Air Zone' campaign was to prohibit cigarette consumption in all indoor areas (except restaurants, bars, cafes).$^{40}$ On 19 July 2009 the ban was expanded to include restaurants, coffee houses, bars and cafes, ensuring that all indoor areas in Turkey are smoke-free. By prohibiting smoking 
indoor, the frequency of both active and passive smoking has been reduced. There was a significant reduction in the prevalence of SHS in all indoor public areas, with the greatest reduction occurring in restaurants $(55.9 \%$ in 2008 and $12.9 \%$ in 2012). Although it is not covered by the law, there has been a significant reduction in the prevalence of SHS in households. Moreover, as of 19 July 2009, Turkey was ranked sixth in the world and the third in Europe in terms of having the most comprehensive tobacco control legislation, behind Bermuda, New Zealand, Uruguay, England and Ireland, according to WHO data. ${ }^{41}$

While, active smoking is a voluntary behaviour, however, exposure to SHS occurs passively and can affect nonsmokers as well. Therefore, in order to properly address SHS exposure, it is critical to identify the factors that contribute to the exposure. ${ }^{13}$ While the demographic, socioeconomic and psychosocial determinants of tobacco use have received considerable attention in the literature, research focusing on SHS determinants is scarce. ${ }^{134243}$

Education is frequently considered the key indication of individual socioeconomic status (SES) and is one of the core determinants of health. ${ }^{445}$ Occupation, income and education are the key indices of SES, which is a multidimensional concept. In the literature, many researchers have preferred education as the primary indicator of SES. Earnings and occupational position may fluctuate with changes in health because educational attainment tends to be stable in early adulthood. Furthermore, whereas educational status may be determined for everyone, occupational status cannot be determined for those who have recently entered or never entered the labour. ${ }^{46}$

Material, behavioural and cognitive theories about the relationship of SES to health and death are all linked to educational attainment. ${ }^{47}$ The relationship between education and health is well-established, with bettereducated people living longer and experiencing fewer ailments throughout their lives. Individuals' incomeearning abilities are directly influenced by their educational attainment, and thus their access to adequate nutrition, shelter, healthcare and other material conditions that can help them live a long and healthy life. Education can also improve one's capacity to use information to make better judgments that will improve one's prospects in life. ${ }^{44}$ A protective impact of educational attainment against drug use and SHS exposure, including alcohol use and binge drinking, has been observed in the literature. ${ }^{49}{ }^{50}$ As a result, research have been conducted in a variety of disciplines, including health, ${ }^{51-53}$ education $^{54-56}$ and the arts. ${ }^{57} 58$ Furthermore, there are studies in different fields of social sciences in which educational differences are discussed. ${ }^{59-61}$

In Turkey, little is known about the extent to which individuals with varying levels of education are exposed to tobacco smoke. As far as we know, this is the first study in Turkey to examine the factors associated with exposure to tobacco smoke according to an individual's educational level. The following constitute this study's research problems; Does the exposure to smoke vary according to an individual's educational level?, Is there a relationship between an individual's demographic characteristics and their exposure to tobacco smoke?, and Are the factors associated with the exposure of tobacco smoke for the individuals with varying educational levels the same?

\section{LITERATURE REVIEW}

Various studies on SHS exposure have been undertaken in various countries, in various fields, on various samples and in various years. According to a Korean study, SHS exposure was associated to frequent alcohol use in young women and long-term cigarette use in men. ${ }^{62} \mathrm{~A}$ Spanish study found that all SHS exposure indicators were moderately strongly correlated with nicotine concentrations in the air. ${ }^{63}$ A Portuguese study examined the short-term effectiveness of a $100 \%$ smoke-free homes intervention programme in avoiding passive tobacco smoke exposure in children. ${ }^{64}$ SHS concentrations in the living room and children's bedrooms in houses with children younger than 13 years old were found to be strongly correlated in a study conducted in Barcelona.$^{65}$ According to a Chilean study, workers in smoking facilities were exposed to more SHS than those in non-smoking areas. ${ }^{66}$ In a study conducted in Bangladesh, children aged 10-12 years were found to be exposed to SHS at home ${ }^{67}$ In a study conducted in China, households exposed to SHS had a higher prevalence of gifting and sharing smokes. ${ }^{68}$ SHS exposure was reported to be common among preschool children and their mothers $(50 \%$ and $7 \%$, respectively) in a study conducted in Taiwan. ${ }^{42}$ In a study conducted in India, it was aimed to address factors associated with current tobacco use and SHS exposure among older adults ( $\geq 60$ years). ${ }^{69}$ According to a study conducted in Ireland, pregnant women who lived with a smoker were approximately four times more likely to be exposed to SHS. $^{70}$

The variables connected to education (education level, education difference, educational achievement, etc) come to the fore in empirical studies on SHS exposure in the literature. In their study, Assari and Bazargan ${ }^{49}$ found that persons with a higher degree were less likely to be exposed to daily SHS. All categories of the variable of educational status were found to be efficient in exposing women to SHS in a study conducted in Turkey. ${ }^{7}$ A study among US adults indicated that those with less education were more likely to be exposed to SHS at work. ${ }^{71}$ According to a study conducted in South Korea, the likelihood of being exposed to SHS decreases as one's educational level rises. ${ }^{72}$ A study conducted in Bangladesh to determine the incidence of SHS exposure at home discovered that education had a significant impact on SHS exposure at home. ${ }^{73}$ According to a study conducted in Australia, the higher one's educational level, the less likely one is to be exposed to SHS at home and elsewhere. ${ }^{74}$ Less educated people were shown to be more susceptible to SHS in a study conducted in Germany. ${ }^{75}$ According to a 
study conducted in Spain, children whose parents have basic and secondary education have higher overall SHS exposure than children whose parents have a university degree. ${ }^{76}$ In a study of non-smoking adult cancer survivors in the USA, it was found that less educated individuals were more exposed to SHS. ${ }^{77}$

In the literature, there are various studies examining the relationship between SHS exposure and education. According to a study conducted in Northern China's Inner Mongolia (Inner Mongolia, Northern China), SHS exposure rates were highest among young women who had never smoked. ${ }^{78}$ In another study conducted in Portugal, it was found that smoking prevalence was higher among parents with lower levels of education, and that children of parents with lower levels of education were more likely to be exposed to SHS at home. ${ }^{79}$ According to a study conducted in Spain, $25.8 \%$ of children are exposed to SHS at home, $4.6 \%$ in the automobile, $8.2 \%$ on public transportation, $31.9 \%$ in kindergarten and $48 \%$ in their free time. The study also discovered that the higher the education level at home, the lower the exposure to SHS. ${ }^{76}$ SHS exposure was found to be relatively high in a study of women with higher education at two Jordanian institutions. ${ }^{80}$ In a study of American adults, it was discovered that educational attainment helped individuals avoid environmental risk factors such as SHS, with blacks and Hispanics having less protective effects against SHS exposure than whites. ${ }^{49}$

\section{METHODS \\ Data}

The survey data for this study, survey data obtained from the Turkish Statistical Institute's 2019 Turkey Health Survey. Turkey Health Survey was conducted with the aim of closing the information gap in the current structure by obtaining data on health indicators, which account for a significant portion of the development indicators used to determine a country's development level. The research is significant as it is the first to reflect the country's overall situation and to enable international comparisons while also shedding light on national requirements. ${ }^{81}$

The stratified two-stage cluster sampling method was used to obtain the data. The first stage sampling unit is comprised of randomly selected blocks from clusters (blocks) containing an average of 100 house addresses proportional to their size; the second sampling unit is comprised of randomly selected household addresses from each selected cluster. The research was conducted in order to provide an overall estimate for Turkey. ${ }^{81}$

Secondary data of individuals aged 15 years and over were employed in the study. The total sample volume has been determined to be 9470 household addresses due to the study's design. From these households, data were gathered from a total of 17084 people.

\section{Outcome variables}

The dependent variable in this study is individuals' exposure to tobacco smoke according to their educational level (illiterate/unschooled, primary school graduates, primary education graduates, high school graduates, university graduates).

This research looked at five different groups, ranging from the least educated to the most educated. Studies investigating educational differences in various fields in the literature were considered to determine the education categories. ${ }^{495052568283}$ In the study, a separate binary logit model was estimated for each education level. Individuals enrolled in the study were assigned the code ' 1 ' if they had been exposed to tobacco smoke and ' 0 ' if they had not.

\section{Independent variables}

This study's independent variables are those that are available in the Turkey Health Survey and emerge as a result of the literature review. The independent variables of this study are as follows; age (34 and under, 35-44, 45-54 and 55+), gender (male, female), marital status (never married, married, divorced/spouse died), employment status (yes, no), general health status (very good/ good, moderate, poor/very bad), receipt of psychosocial support health services from primary care health institutions (yes, no), alcohol use (yes, no), tobacco use status (yes, no) and the ability to afford treatment (yes, no).

In this study, the age variable was included in the model as a qualitative variable. The inclusion of age as a qualitative variable in the model allows for a more detailed examination of its variation across age groups. ${ }^{84} 85$ Most people complete their education at an early age and continue it throughout their adult lives. ${ }^{86}$ Therefore, 34 and under is considered as a category. In order to avoid the multicollinearity problem in the models, 55 and above are considered as a category.

Ordinal and nominal variables were defined as dummy variables to examine the effects of all variables included in the binary logistic regression model on their categories. ${ }^{87}$

\section{Analysis method}

Survey statistics in Stata V.15 (Stata Corporation) were used to account for the complex sampling design and weights. Weighted analysis was conducted.$^{88}$ The primary objective was to ascertain, the tobacco exposure of the participants in the research, as well as the frequency and percentages of the independent variables. In this study, the binary logistic regression method was used to investigate differences in tobacco exposure by educational level.

Binary logistic regression was conducted to determine the risk factors associated with tobacco smoke exposure. In cases where the result (dependent) variable has two options (binary/dichotomy), this analysis is used to investigate the relationship between the dependent variable and the independent variable(s). Binary logistic regression not only enables the statistical significance of each 
independent variable as a risk factor to be evaluated, but also OR to be calculated. ${ }^{89}$

\section{Patient and public involvement}

Patients and/or the public were not involved in the design, or conduct, or reporting, or dissemination plans of this research.

\section{RESULTS}

\section{Descriptive statistics}

This study determined that individuals who are illiterate/ unschooled were exposed to tobacco smoke at a rate of $32.61 \%$, primary school graduates at a rate of $34.32 \%$, primary education graduates at a rate of $41.75 \%$, high school graduates at a rate of $41.04 \%$ and university graduates at a rate of $40.34 \%$.

Table 1 summarises the findings regarding the factors that influence an individual's exposure to tobacco smoke based on their education level in Turkey.

\section{Model estimation}

In the study, it was tested whether there was a multicollinearity between the independent variables to be included in the binary logistic regression model. It is thought that those with a variance inflation factor values of 5 or greater exhibit moderate multicollinearity, while those of 10 or greater exhibit a high degree of multicollinearity ${ }^{59}$ There is no variable in this study that causes the problem of multicollinearity between the variables online supplemental appendix 1 .

The estimated binary logistic regression model's results are given in table 2. The entire model estimated for all participants revealed a correlation between education level and exposure to tobacco smoke. According to table 2, the variables age $(55+)$, marital status (never married) and tobacco use were all found to be significant in Model 1 , which was estimated for illiterate/unschooled individuals. Age, marital status (divorced/spouse died), general health status (moderate), receiving psychosocial support and tobacco use were all significant variables in Model 2, which was estimated for primary school graduates. Age, gender, general health status (moderate), employment status and tobacco use were all significant variables in Model 3, which was estimated for primary education graduates. The variables age $(45-54,55+)$, gender, marital status (never married), general health status (moderate) and tobacco use were found to be significant in Model 4, which was estimated for high school graduates. Finally, it was observed that the variables of age, gender, marital status (never married) and tobacco use were significant in Model 5, which was estimated for university graduates.

Table 3 summarises the marginal effects of factors related to tobacco smoke exposure according to education levels are given in table 3 .

When it comes to illiterate/unschooled individuals, those aged $45-54$ is $23.3 \%$ less likely to be exposed to tobacco smoke than those aged 34 and under (reference group). Similarly, an illiterate person aged 55 or over is $91.6 \%$ less likely to be exposed to tobacco smoke than someone aged 34 or under. When the marital status variable is examined, it is discovered that an illiterate individual who has never been married is $39.3 \%$ less likely than a married individual to be exposed to tobacco smoke. A tobacco user who is illiterate is $76.1 \%$ more likely to be exposed to tobacco smoke than a non-user.

Among primary school graduates, an individual aged $35-44$ is $14.2 \%$ less likely to be exposed to tobacco smoke than an individual aged 34 or under (reference group). Similarly, a primary school graduate aged 55 or over is $48.1 \%$ less likely to be exposed to tobacco smoke than an individual aged 34 or under. When the marital status variable is examined, it is discovered that a primary school graduate with a marital status of divorced/spouse died is $19.8 \%$ less likely to be exposed to tobacco smoke than a married individual. A primary school graduate with a moderate general health status is $11.7 \%$ more likely to be exposed to tobacco smoke than an individual with a very good/good general health status. Similarly, a primary school graduate receiving psychosocial support is $14.5 \%$ more likely to be exposed to tobacco smoke than those who do not receive psychosocial support. A primary school graduate who uses tobacco products is $63.4 \%$ more likely to be exposed to tobacco smoke than an individual who does not.

Among primary education graduates, an individual aged $35-44$ is $23.6 \%$ less likely to be exposed to tobacco smoke than an individual aged 34 or under (reference group). Similarly, a primary education graduate aged 55 or over is $56 \%$ less likely to be exposed to tobacco smoke than an individual aged 34 or under. A woman who is a primary education graduate is $24.8 \%$ less likely to be exposed to tobacco smoke than a man of the same education level. It was discovered that the probability of being exposed to tobacco smoke is $16 \%$ higher for a primary education graduate with a moderate general health status than an individual with a very good/good general health status. An employed individual with a primary education degree is $13.4 \%$ less likely to be exposed to tobacco smoke than an unemployed individual. It was discovered that a primary education graduate who uses tobacco products is $53.9 \%$ more likely to be exposed to tobacco smoke than an individual who does not.

Among high school graduates, an individual in the $45-54$ age range is $25.4 \%$ less likely to be exposed to tobacco smoke than an individual aged 34 or under (reference group) and an individual aged 55 or over is $31 \%$ less likely to be exposed to tobacco smoke than an individual aged 34 or under. An unmarried high school graduate is $27.1 \%$ more likely to be exposed to tobacco smoke than a married individual. It was discovered that a high school graduate with a moderate general health status is $10.6 \%$ more likely to be exposed to tobacco smoke than an individual with a very good/good general health condition. It is seen that a high school graduate who uses tobacco products is $30.3 \%$ more likely to be 
Table 1 Findings regarding factors affecting individuals' exposure to tobacco smoke by education level

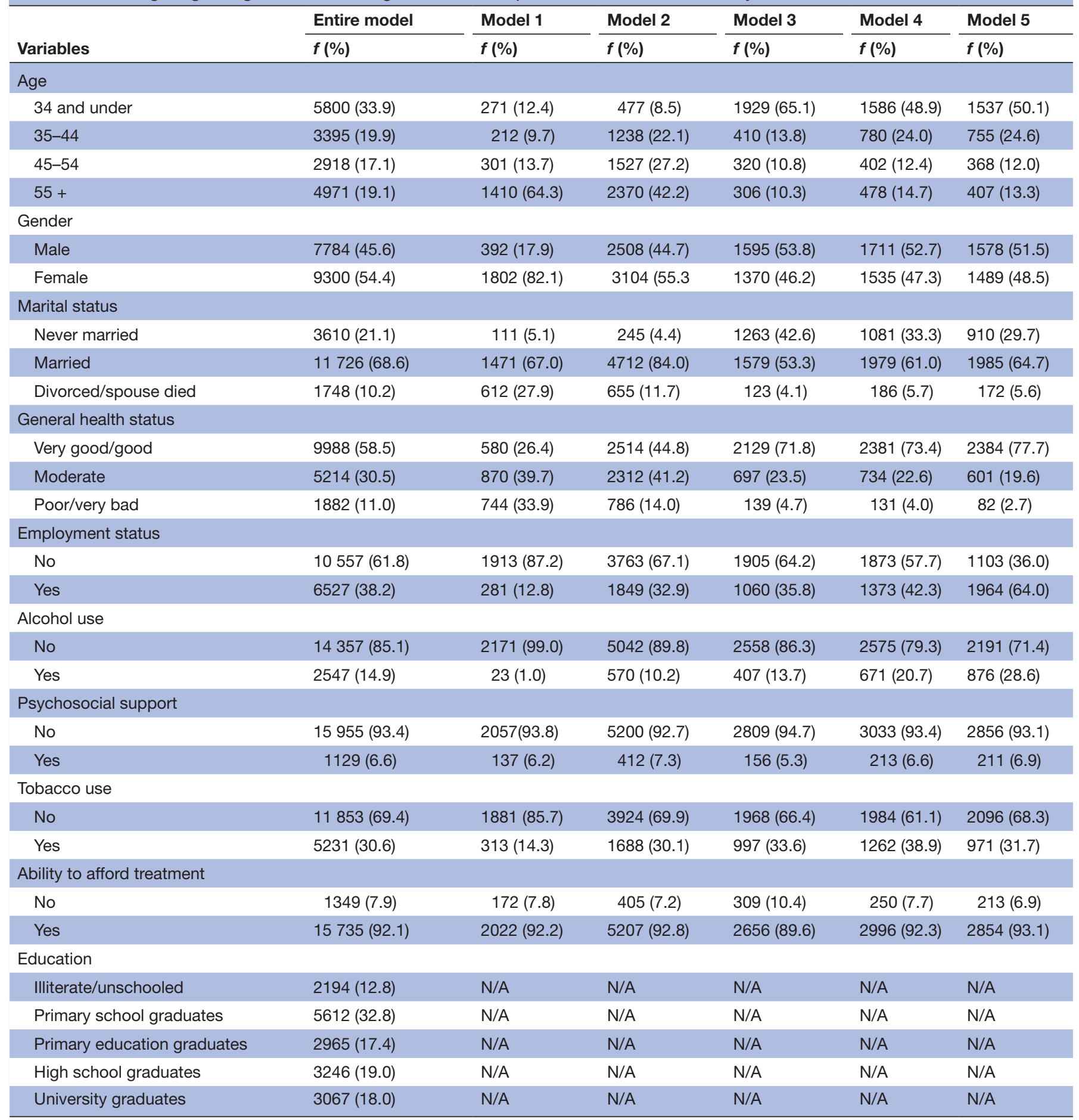

Model 1: Illiterate/ unschooled, Model 2: Primary school graduates, Model 3: Primary education graduates, Model 4: High school graduates; Model 5: University graduates.

exposed to tobacco smoke than an individual who does not.

When university graduates are considered, an individual aged $45-54$ is $21.6 \%$ less likely to be exposed to tobacco smoke than an individual aged 34 or under (reference group) and an individual aged 55 or over is $54 \%$ less likely to be exposed to tobacco smoke than an individual aged 34 or under. The findings demonstrate that a university graduate who has never been married is $26.4 \%$ more likely to be exposed to tobacco smoke than a married individual. A female university graduate is $15.8 \%$ less likely to be exposed to tobacco smoke than a man of the same education level. It was also observed that a university graduate who uses tobacco products is $32.7 \%$ more likely to be exposed to tobacco smoke than an individual who does not. 
Table 2 Estimated model results for factors affecting individuals' exposure to tobacco smoke by education level

\begin{tabular}{|c|c|c|c|c|c|c|}
\hline & Entire model & Model 1 & Model 2 & Model 3 & Model 4 & Model 5 \\
\hline Variables & $\beta$ & $\beta$ & $\beta$ & $\beta$ & $\beta$ & $\beta$ \\
\hline \multicolumn{7}{|c|}{ Age (reference category: 34 and under) } \\
\hline $45-54$ & $-0.388^{*}(0.065)$ & $-0.449(0.224)$ & $-0.334 \ddagger(0.131)$ & $-0.523^{*}(0.159)$ & $-0.418^{\star}(0.154)$ & $-0.408^{*}(0.145)$ \\
\hline $55+$ & $-0.919^{*}(0.069)$ & $-1.455^{\star}(0.205)$ & $-0.744^{*}(0.135)$ & $-0.874^{*}(0.183)$ & $-0.502^{\star}(0.159)$ & $-0.836^{*}(0.161)$ \\
\hline \multicolumn{7}{|l|}{ Gender (reference category: male) } \\
\hline \multicolumn{7}{|c|}{ Marital status (reference category: married) } \\
\hline Never married & $0.263^{\star}(0.056)$ & $-0.552 \ddagger(0.263)$ & $0.240(0.160)$ & $0.051(0.113)$ & $0.466^{*}(0.113)$ & $0.451^{*}(0.102)$ \\
\hline Divorced/spouse died & $-0.129+(0.072)$ & $-0.077(0.158)$ & $-0.289 \ddagger(0.115)$ & $0.321(0.232)$ & $0.067(0.199)$ & $0.076(0.199)$ \\
\hline \multicolumn{7}{|c|}{ General health status (reference category: very good/good) } \\
\hline Moderate & $0.128^{*}(0.046)$ & $-0.128(0.152)$ & $0.178^{*}(0.077)$ & $0.282 \ddagger(0.112)$ & $0.184 \dagger(0.104)$ & $-0.084(0.114)$ \\
\hline \multicolumn{7}{|l|}{ Alcohol use (reference category: no) } \\
\hline Yes & $0.038(0.055)$ & $-0.807(0.583)$ & $0.150(0.115)$ & $-0.060(0.134)$ & $0.122(0.105)$ & $0.002(0.096)$ \\
\hline \multicolumn{7}{|c|}{ Psychosocial support (reference category: no) } \\
\hline Yes & $0.140 \dagger(0.077)$ & $-0.286(0.249)$ & $0.228 \dagger(0.132)$ & $0.283(0.196)$ & $0.143(0.173)$ & $0.011(0.169)$ \\
\hline \multicolumn{7}{|c|}{ Tobacco use (reference category: no) } \\
\hline Yes & $0.837^{\star}(0.043)$ & $1.312^{*}(0.173)$ & $1.019^{*}(0.078)$ & $0.990^{\star}(0.105)$ & $0.526^{\star}(0.092)$ & $0.570^{*}(0.093)$ \\
\hline \multicolumn{7}{|c|}{ Ability to afford treatment (reference category: no) } \\
\hline Yes & $0.036(0.070)$ & $-0.163(0.214)$ & $0.177(0.130)$ & $0.005(0.146)$ & $0.216(0.166)$ & $-0.146(0.171)$ \\
\hline \multicolumn{7}{|c|}{ Education (reference category: illiterate/unschooled) } \\
\hline Primary school graduates & $-0.255^{\star}(0.068)$ & N/A & N/A & $\mathrm{N} / \mathrm{A}$ & $\mathrm{N} / \mathrm{A}$ & $\mathrm{N} / \mathrm{A}$ \\
\hline
\end{tabular}

Model 1: Illiterate/ unschooled, Model 2: Primary school graduates, Model 3: Primary education graduates, Model 4: High school graduates; Model 5: University graduates. ${ }^{*} \mathrm{p}<0.01$.

$t p<0.10$.

$\neq p<0.05$.

\section{DISCUSSION}

Tobacco use causes significant health problems not only for those who use them, but also for those who do not, as tobacco smoke spreads into the environment. Each year, new evidence regarding the health risks associated with the exposure of others to tobacco smoke is obtained. Therefore, it is necessary to understand the factors that contribute to tobacco smoke in order to reduce the prevalence of SHS.

This study used data from 17084 individuals who participated in the Turkish Statistical Institute's 2019 Turkey Health Survey. The factors affecting an individual's exposure to tobacco smoke in Turkey according to their educational level were determined in this study using binary logistic regression analysis.

The variables of education level, age, gender, marital status, general health, getting psychosocial assistance and tobacco smoking status were found to be associated with exposure to tobacco smoke in Entire Model, which included the education variable. Furthermore, it was found in the study that the importance and effect of the variables in tobacco smoke exposure change depending on the people's educational level. As a result, risk variables for tobacco smoke exposure have been determined based on educational attainment.

In all of the models, it was determined that there was a relationship between people's age and their exposure to tobacco smoke. It has been determined that people aged 45-54 and 55 and above are less likely to be exposed to tobacco smoking than people aged 34 and below (reference group) in Model 1 (illiterate/unschooled) and Model 4 (high school graduates). All age categories were found to be statistically significant in Model 2 (primary school graduates), Model 3 (primary education graduates) and Model 5 (university graduates). It has been determined that the probability of exposure to tobacco smoke decreases as age increases. 
Table 3 Marginal effects (ME) of factors associated with individuals' exposure to tobacco smoke by education level

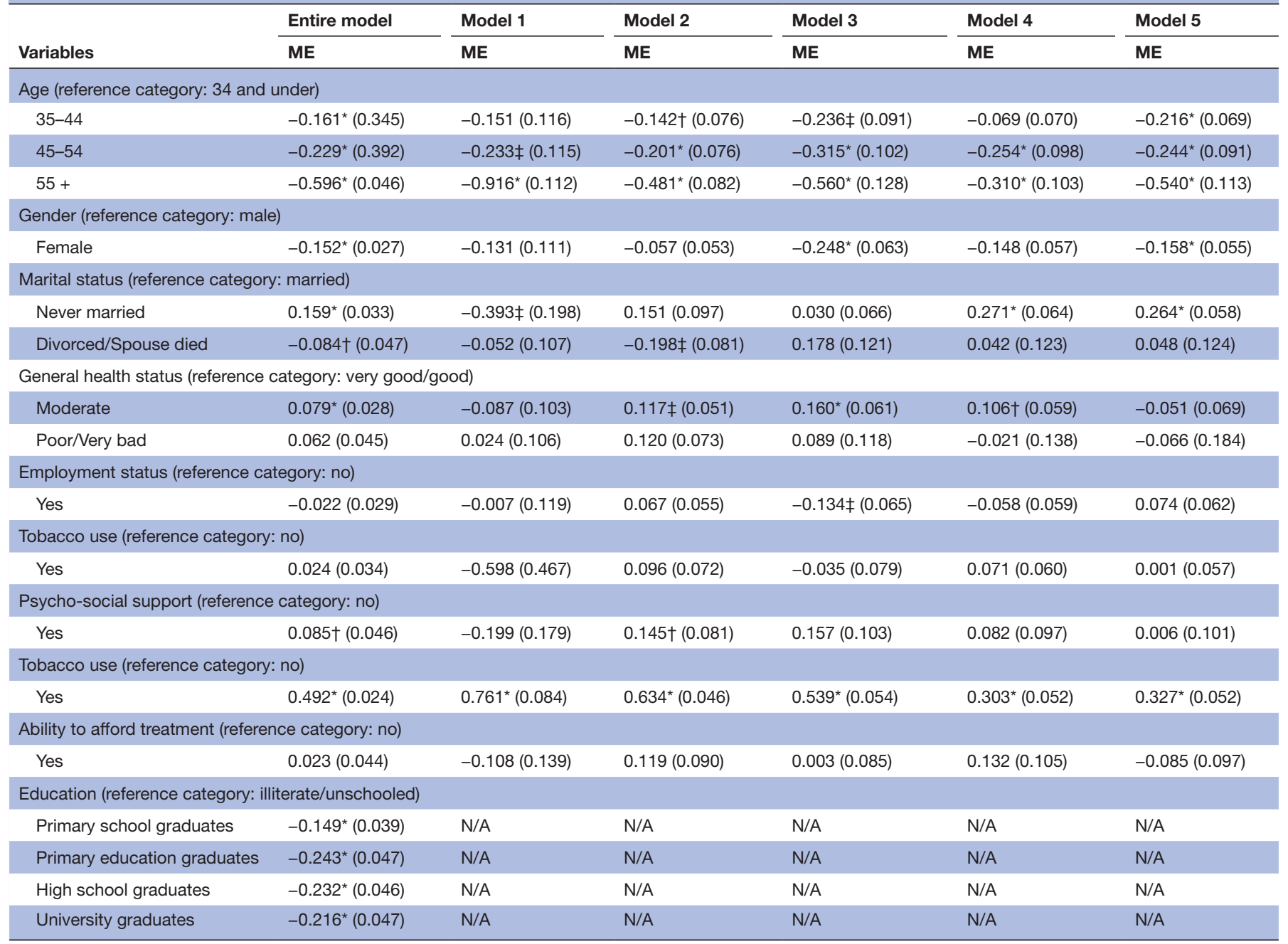

Model 1: Illiterate/ unschooled, Model 2: Primary school graduates, Model 3: Primary education graduates, Model 4: High school graduates; Model 5: University graduates. ${ }^{*} \mathrm{p}<0.01$.

There was a relationship between individuals' gender and exposure to tobacco smoke only in Model 3 (primary education graduates) and Model 5 (university graduates). Women were found to be less likely than men to be exposed to tobacco smoke in these models.

There was a relationship between people's marital status and their exposure to tobacco smoke in all models. It has been determined that an unmarried individual is less likely to be exposed to tobacco smoke than a married individual in Model 1 (illiterate/unschooled). It has been determined that an unmarried individual is more likely to be exposed to tobacco smoke than a married individual in Model 4 (high school graduates) and Model 5 (university graduates). In Model 2 (primary school graduates), it was determined that a divorced/widowed person is less likely than a married person to be exposed to tobacco smoke.

Only in Model 2 (primary school graduates), Model 3 (primary education graduates) and Model 4 (high school graduates), it was determined that there was a relationship between the general health status of individuals and exposure to tobacco smoke. According to these models, an individual with a moderate general health status is more likely to be exposed to tobacco smoke than someone with a very good general health status.

It was determined that there was a relationship between persons' employment status and SHS exposure only in Model 3 (primary education graduates). According to this model, a working individual is less likely to be exposed to tobacco smoke than a non-working individual.

Only in Model 2 (primary school graduates), there was a relationship between receiving psychosocial support and exposure to tobacco smoke. According to this model, an individual who received psychosocial support was more likely to be exposed to tobacco smoke than an individual who did not receive psychosocial support.

It was determined in all models that there was a relationship between people's tobacco use status and their exposure to tobacco smoke. According to these models, an individual who smokes tobacco is more likely to be 
exposed to tobacco smoke than someone who does not smoke.

The study discovered that as one's age increased, the likelihood of being exposed to tobacco decreased. Similar results were obtained in other studies. ${ }^{72} 747590$ As people age, they realise that tobacco use is a risk factor for a variety of chronic diseases and develop a greater awareness of health issues such as quitting smoking. ${ }^{91}$ Numerous studies have revealed that individuals with high levels/dangerous/risky use of tobacco appear to be older than their actual age. ${ }^{92}$ Furthermore, the reason for the decline in tobacco use as individuals age may be their obsession with looking young, which makes them more cautious about tobacco product use. ${ }^{7}$ On the other hand, as people age, they take their health more seriously and have more time and energy to devote to anti-tobacco campaigns. In this context, as the prevalence of people who have given up tobacco products increases with age, the probability of being exposed to tobacco smoke decreases. ${ }^{91}$

Individuals who receive psychosocial support are more likely to be exposed to tobacco smoke than those who do not receive psychosocial support. Similar findings have been reported in other studies. ${ }^{9394}$ Interventions aimed at reducing SHS exposure can help people's mental health. Individual-level therapies, such as education regarding the dangers of SHS exposure and avoidance techniques, may also be explored as supplementary strategies for depression management. ${ }^{7}$

In the study, individuals with a moderate general health status were found to be more exposed to tobacco smoke than those with a very good/good general health condition. According to studies, individuals who care about their health are more conscientious about avoiding exposure to tobacco smoke. ${ }^{9394}$

Individuals who are employed were found to be less exposed to tobacco smoke than those who are unemployed. According to a study that reached a similar conclusion, the risk of exposure to tobacco increases as unemployed individuals stay at home longer. ${ }^{95}$ However, there are studies that conclude that employed individuals are more exposed to tobacco smoke than unemployed individuals. ${ }^{750}$

Individuals who have been exposed to tobacco use for an extended period of time develop similar health problems to those who use tobacco products. According to the study, those who use tobacco products are more exposed to tobacco smoke than those who do not. Several studies in the literature reported similar findings. ${ }^{73} 88$

Individuals who are illiterate and have never married were determined to be less likely to be exposed to tobacco smoke than married individuals. Similar findings have been reported in the literature. ${ }^{74}$ On the other hand, the study discovered that individuals who graduated from primary school with their marital status as divorced/ spouse died were less exposed to tobacco smoke than married individuals. Similar results were obtained in some studies. ${ }^{96}{ }^{97}$ Studies have suggested that this may be due to the fact that the majority of these individuals live alone and are thus less exposed to smoking at home. ${ }^{91}$

According to the study, men are more exposed to tobacco smoke than women are. Similar results were obtained in other studies. ${ }^{75}$ On the other hand, some studies in the literature argue that women are more exposed to tobacco smoke than men. Studies have reported that this may be highly correlated with women's SES. ${ }^{74}$ Additionally, some studies have discovered that women are more likely to be exposed to SHS because they spend more time doing housework in regulated industries that are less likely to challenge SHS policies. ${ }^{98}$

This study is not without limitations. To begin, the study relies on secondary data. The variables required for statistical analysis are those found in the data set. Additionally, some variables such as individuals' occupations, home ownership status, levels of exposure to tobacco smoke by parents, siblings, as well as other household members and friends were not included in the analysis. Furthermore, because the data set did not include information about the location of tobacco smoke exposure, this study focused on general SHS exposure. The distinction between SHS-exposed locations such as homes, public places, workplaces, restaurants and bars was omitted. Second, because tests to determine individuals' exposure to tobacco smoke could not be conducted in a laboratory setting, the study relied on the women's own responses. The data obtained might be biased as a result of this data collection method.

This limitation may be overcome in the future by more objective measures of SHS exposure. Future research should further explore determinants that cannot be identified qualitatively. Objective measurement of smoke inhalation can be helpful in avoiding reporting bias. In addition, studies must account for variation within countries and acknowledge that there may be significant differences in prevalence and determinants between regions within the same country.

Future research can identify key factors influencing an individual's social acceptability of SHS exposure. Identifying these factors is critical when planning and designing tobacco prevention programmes that target SHS exposure. If health risks are communicated effectively and guided by the demands of (several) target groups, the social acceptability of tobacco exposure will be further reduced.

\section{CONCLUSION}

As a result of the study, it is emphasised that men, young individuals, individuals with moderate and very good general health status, those who use tobacco, those who are unemployed and those who receive psychosocial support should be targeted. These groups require additional protection against SHS exposure. Appropriate strategies for reducing SHS exposure should be developed, taking into account public health strategies for increasing awareness of the adverse health effects of SHS 
exposure and the determinants of tobacco exposure. Turkey's National Tobacco Control Program Action Plan, coordinated by the Ministry of Health, took effect on 27 January 2015. The strategies outlined in said action plan include ensuring that society exhibits the right attitudes and behaviours in response to violations by increasing awareness that protection fromSHS exposure is a human right in terms of health, enacting necessary legislative changes to expand the areas where tobacco and tobacco products are prohibited, and increasing public awareness and advocacy on the issue. In addition, the National Tobacco Control Program Action Plan includes strategies for establishing the necessary system for determining and regularly monitoring the level of SHS exposure in society, as well as for initiating and maintaining social support for passive smoke prevention in homes/living areas/private properties.

Policies prohibiting tobacco use in public places are necessary for a variety of reasons. Primarily, the public is uncomfortable with SHS exposure and views it as harmful to health. However, the majority of non-smokers take no personal precautions to avoid exposure to SHS. Government agencies must take action to protect non-smokers. Moreover, restricting tobacco use in public places may increase the likelihood that people will use fewer tobacco products or will quit entirely.

Acknowledgements The authors wish to express their gratitude to thank the Turkish Statistical Institute for providing the data. The views and opinions expressed in this manuscript are those of the authors only and do not necessarily represent the views, official policy or position of the Turkish Statistical Institute.

Contributors ÖA conceived and led the design and development of the study proposal. ÖA and ŞÜ supervised data collection, led the data analysis and drafting the manuscript. ŞÜ made substantial contributions to the conceptualisation and design of the study, data interpretations and writing the manuscript. All authors read and approved the final version of the manuscript.

Funding The authors have not declared a specific grant for this research from any funding agency in the public, commercial or not-for-profit sectors.

Competing interests None declared.

Patient consent for publication Not applicable.

Ethics approval This study was accomplished by using data of the survey titled Turkey Health Survey conducted by Turkey Statistical Institute. Therefore, ethical approval was not required for this study. We used secondary data for this study. In order to use the micro data set from the Turkey Health Survey, the official permission was obtained from the Turkish Statistical Institute. In addition, a 'Letter of Undertaking' was given to the Turkish Statistical Institute for the use of the data subjected to the study.

Provenance and peer review Not commissioned; externally peer reviewed.

Data availability statement Data may be obtained from a third party and are not publicly available. The data underlying this study is subject to third-party restrictions by the Turkey Statistical Institute. Data are available from the Turkish Statistical Institute (bilgi@tuik.gov.tr) for researchers who meet the criteria for access to confidential data. The authors of the study did not receive any special privileges in accessing the data.

Supplemental material This content has been supplied by the author(s). It has not been vetted by BMJ Publishing Group Limited (BMJ) and may not have been peer-reviewed. Any opinions or recommendations discussed are solely those of the author(s) and are not endorsed by BMJ. BMJ disclaims all liability and responsibility arising from any reliance placed on the content. Where the content includes any translated material, BMJ does not warrant the accuracy and reliability of the translations (including but not limited to local regulations, clinical guidelines, terminology, drug names and drug dosages), and is not responsible for any error and/or omissions arising from translation and adaptation or otherwise.

Open access This is an open access article distributed in accordance with the Creative Commons Attribution Non Commercial (CC BY-NC 4.0) license, which permits others to distribute, remix, adapt, build upon this work non-commercially, and license their derivative works on different terms, provided the original work is properly cited, appropriate credit is given, any changes made indicated, and the use is non-commercial. See: http://creativecommons.org/licenses/by-nc/4.0/.

\section{ORCID iDs}

Ömer Alkan http://orcid.org/0000-0002-3814-3539

Şeyda Ünver http://orcid.org/0000-0002-2310-4545

\section{REFERENCES}

1 Alkan Ö, Demir A. Investigation and detection of risk factors related to the period without tobacco consumption. Addicta: Turkish $\mathrm{J}$ Addict 2019;6:99-115.

2 WHO. Who global report: mortality attributable to tobacco. Switzerland: Geneva, 2012.

3 Yousuf H, Hofstra M, Tijssen J, et al. Estimated worldwide mortality attributed to secondhand tobacco smoke exposure, 1990-2016. JAMA Netw Open 2020;3:e201177.

4 WHO. Enforcing bans on tobacco advertising, promotion and sponsorship: who report on the global tobacco epidemic. Switzerland: Geneva, 2013.

5 Rodgman A, Perfetti TA. The chemical components of tobacco and tobacco smoke. 2nd edn. New York: CRC Press, 2013.

6 Apelberg BJ, Hepp LM, Avila-Tang E, et al. Environmental monitoring of secondhand smoke exposure. Tob Control 2013;22:147-55.

7 Alkan Ö, Ş Ünver. Tobacco smoke exposure among women in turkey and determinants. J Substance Use 2021;27:43-9.

8 Dinas PC, Metsios GS, Jamurtas AZ, et al. Acute effects of secondhand smoke on complete blood count. Int J Environ Health Res 2014;24:56-62.

9 Öberg M, Jaakkola MS, Woodward A, et al. Worldwide burden of disease from exposure to second-hand smoke: a retrospective analysis of data from 192 countries. Lancet 2011;377:139-46.

10 Barnoya J, Glantz SA. Cardiovascular effects of secondhand smoke: nearly as large as smoking. Circulation 2005;111:2684-98.

11 Simons E, To T, Moineddin R, et al. Maternal second-hand smoke exposure in pregnancy is associated with childhood asthma development. J Allergy Clin Immunol Pract 2014;2:201-7.

12 Faber T, Kumar A, Mackenbach JP, et al. Effect of tobacco control policies on perinatal and child health: a systematic review and metaanalysis. Lancet Public Health 2017;2:e420-37.

13 Sun LY, Cheong HK, Lee EW, et al. Affecting factors of secondhand smoke exposure in Korea: Focused on different exposure locations. J Korean Med Sci 2016;31:1362-72.

14 Hoffman SJ, Tan C. Overview of systematic reviews on the healthrelated effects of government tobacco control policies. BMC Public Health 2015;15:1-11.

15 Hyland A, Barnoya J, Corral JE. Smoke-free air policies: past, present and future. Tob Control 2012;21:154-61.

16 Jones MR, Barnoya J, Stranges S, et al. Cardiovascular events following smoke-free legislations: an updated systematic review and meta-analysis. Curr Environ Health Rep 2014;1:239-49.

17 WHO. Who framework convention on tobacco control. Switzerland: Geneva, 2003.

18 Zasimova L. Analysis of non-compliance with smoke-free legislation in Russia. Int J Public Health 2019;64:413-22.

19 Perkins R, Neumayer E. Adoption and compliance in second-hand smoking bans: a global econometric analysis. Int J Public Health 2014;59:859-66.

20 Feldman EA, Bayer R. The triumph and tragedy of tobacco control: a tale of nine nations. Annu Rev Law Soc Sci 2011;7:79-100.

21 Vathesatogkit P, Charoenca N. Tobacco control: lessons learnt in Thailand. Indian J Public Health 2011;55:228-33.

22 Ali I. Adoption of the tobacco control Regulations - Legislative instrument (LI) 2247 to reduce the burden of NCDs and to advance WHO FCTC implementation in Ghana. Tob Induc Dis 2018;16:A428.

23 Singh A, Okello G, Semple S, et al. Exposure to secondhand smoke in hospitality settings in Ghana: evidence of changes since implementation of smoke-free legislation. Tob Induc Dis 2020;18:1-10.

24 Peruga A, Fu M, Molina X, et al. Night entertainment venues comply poorly with the smoke-free law in Chile. Gac Sanit 2021;35:402-4. 
25 Hone T, Szklo AS, Filippidis FT, et al. Smoke-free legislation and neonatal and infant mortality in Brazil: longitudinal quasiexperimental study. Tob Control 2020;29:312-9.

26 Carrión-Valero F, Quiles-Izquierdo J, González-Monte C, et al. Impact of the 2005 and 2010 Spanish smoking laws on hospital admissions for tobacco-related diseases in Valencia, Spain. Public Health 2020;180:29-37.

27 Mallma P, Carcamo C, Kaufman JS. The impact of anti-tobacco legislation on birth weight in Peru. Glob Health Res Policy 2020;5:1-10.

28 Grace C. 15.7 Legislation to ban smoking in public spaces. In: Winstanley MH, Scollo M, eds. Tobacco in Australia: facts and issues. Cancer Council Victoria, 2019.

29 Dubray Jet al. Formative evaluation of the smoke-free Ontario act: comparison of baseline and post-SFOA measurements. special report series. Toronto, ON: Ontario Tobacco Research Unit, 2007.

30 Repace J, Zhang B, Bondy SJ, et al. Air quality, mortality, and economic benefits of a smoke - free workplace law for non-smoking Ontario bar workers. Indoor Air 2013;23:93-104.

31 Galán I, Mata N, Estrada C, et al. Impact of the" Tobacco control law" on exposure to environmental tobacco smoke in Spain. BMC Public Health 2007;7:1-7.

32 Thrasher JF, Swayampakala K, Arillo-Santillán E, et al. Differential impact of local and federal smoke-free legislation in Mexico: a longitudinal study among adult smokers. Salud Publica Mex 2010;52:S244-53.

33 Raute LJ, Gupta PC, Pednekar MS. Smoking ban and indoor air quality in restaurants in Mumbai, India. Indian J Occup Environ Med 2011:15:68-72.

34 Braverman MT, Aarø LE, Hetland J. Changes in smoking among restaurant and bar employees following Norway's comprehensive smoking ban. Health Promot Int 2008;23:5-15.

35 Lemstra M, Neudorf C, Opondo J. Implications of a public smoking ban. Can J Public Health 2008;99:62-5.

36 Gallus S, Zuccaro P, Colombo P, et al. Smoking in Italy 2005-2006: effects of a comprehensive national tobacco regulation. Prev Med 2007:45:198-201.

37 Guerrero F, Santonja F-J, Villanueva R-J. Analysing the Spanish smoke-free legislation of 2006: a new method to quantify its impact using a dynamic model. Int J Drug Policy 2011;22:247-51.

38 Mullally BJ, Greiner BA, Allwright S, et al. The effect of the Irish smoke-free workplace legislation on smoking among bar workers. Eur J Public Health 2009;19:206-11.

39 Kaplan B, Carkoglu A, Ergor G, et al. Evaluation of Secondhand smoke using PM2.5 and observations in a random stratified sample in hospitality venues from 12 cities. Int J Environ Res Public Health 2019;16:1381-9.

40 Kaplan B, Grau-Perez M, Çarkoglu A, et al. Smoke-free Turkey: evaluation of outdoor areas of public places. Environ Res 2019;175:79-83.

41 Ministry of Health. Küresel yetişkin tütün araștırması Türkiye 2012. 948. Ankara: Sağlık Bakanlığı (Ministry of Health) Yayın, 2014.

42 Lin P-L, Huang H-L, Lu K-Y, et al. Second-Hand smoke exposure and the factors associated with avoidance behavior among the mothers of pre-school children: a school-based cross-sectional study. BMC Public Health 2010;10:1-9.

43 Shwarz M, Collins BN, Nair US. Factors associated with maternal depressive symptoms among low-income, African American smokers enrolled in a secondhand smoke reduction programme. Ment Health Fam Med 2012;9:275-87.

44 Galea S, Ahern J, Tracy M, et al. Education inequality and use of cigarettes, alcohol, and marijuana. Drug Alcohol Depend 2007;90:S4-15.

45 Adler NE, Newman K. Socioeconomic disparities in health: pathways and policies. Health Aff 2002;21:60-76.

46 Kitagawa Evelyn M, Hauser Philip M. Differential mortality in the United States: a study in socioeconomic epidemiology. Cambridge: Harvard University Press, 1973.

47 Christenson BA, Johnson NE. Educational inequality in adult mortality: an assessment with death certificate data from Michigan. Demography 1995;32:215-29.

48 Hemingway H, Shipley M, Macfarlane P, et al. Impact of socioeconomic status on coronary mortality in people with symptoms, electrocardiographic abnormalities, both or neither: the original Whitehall study 25 year follow up. J Epidemiol Community Health 2000;54:510-6.

49 Assari S, Bazargan M. Unequal effects of educational attainment on workplace exposure to second-hand smoke by race and ethnicity; minorities' diminished returns in the National health interview survey (NHIS). J Med Res Innov 2019;3:e000179.
50 Assari S, Farokhnia M, Mistry R. Education attainment and alcohol binge drinking: diminished returns of Hispanics in Los Angeles. Behav Sci 2019;9:1-11.

51 Yu Y. Educational differences in obesity in the United States: a closer look at the trends. Obesity 2012;20:904-8.

52 Gadeyne S, Deboosere P, Vandenheede H, et al. Does birth history account for educational differences in breast cancer mortality? A comparison of premenopausal and postmenopausal women in Belgium. Int J Cancer 2012;131:2878-85.

53 Marcu A, Lyratzopoulos G, Black G, et al. Educational differences in likelihood of attributing breast symptoms to cancer: a vignette-based study. Psychooncology 2016;25:1191-7.

54 Rattadilok P. Sino-UK educational differences: the impacts of cultures and the current educational curricular on students in computer science. In: Carter J, Rosen C, eds. Transnational higher education in computing courses. Springer., 2019: 39-59.

55 Antunes P, Xiao L, Pino JA. Assessing the impact of educational differences in $\mathrm{HCl}$ design practice. Int $J$ Technol Des Educ 2014;24:317-35.

56 Huang G, Guo F, Chen G. Educational differences of healthy life expectancy among the older adults in China: a multidimensional examination using the multistate life table method. Educ Gerontol 2019;45:624-35.

57 Casanova López O, Serrano Pastor RMM, Casanova O. La Educación musical en El actual currículo español. Qué formación recibe El alumnado en La enseñanza Primaria? Rev Electrón Complut Investig Educ Music 2018;15:3-17.

58 Miettinen L, Gluschankof C, Karlsen S, et al. Initiating mobilizing networks: mapping intercultural competences in two music teacher programmes in Israel and Finland. Res Stud Music Educat 2018;40:67-88.

59 Ünver Ş, Alkan Ö. Determinants of e-commerce use at different educational levels: empirical evidence from turkey. Int J Adv Comp Sci Applicat 2021;12:40-9.

60 Huang $\mathrm{Y}$, Gong H. Educational expectations of left-behind children in China: determinants and gender differences. Appl Res Qual Life 2021;39:1-23.

61 Brdesee $\mathrm{H}$, Alsaggaf $\mathrm{W}$. Is there a real need for the preparatory years in higher education? an educational data analysis for college and future career readiness. Soc Sci 2021;10:396-16.

62 Jeong BY, Lim MK, Yun EH, et al. Tolerance for and potential indicators of second-hand smoke exposure among nonsmokers: a comparison of self-reported and cotinine verified second-hand smoke exposure based on nationally representative data. Prev Med 2014;67:280-7.

63 Arechavala T, Continente X, Pérez-Ríos M, et al. Validity of selfreported indicators to assess secondhand smoke exposure in the home. Environ Res 2018;164:340-5.

64 Precioso Jet al. Exposição de crianças AO fumo ambiental do tabaco: avaliação de programa preventivo. Psicologia, Saúde e Doenças 2017;18:591-601.

65 Arechavala T, Continente X, Pérez-Ríos M, et al. Second-hand smoke exposure in homes with children: assessment of airborne nicotine in the living room and children's bedroom. Tob Control 2018;27:399-406.

66 Parro J, Aceituno P, Droppelmann A, et al. Secondhand tobacco smoke exposure and pulmonary function: a cross-sectional study among non-smoking employees of bar and restaurants in Santiago, Chile. BMJ Open 2017;7:e017811.

67 Siddiqi K, Huque R, Jackson C, et al. Children learning about secondhand smoke (CLASS II): protocol of a pilot cluster randomised controlled trial. BMJ Open 2015;5:e008749.

$68 \mathrm{Xu}$ Y, Xu S, Wu Q, et al. Association between secondhand smoke exposure at home and cigarette gifting and sharing in Zhejiang, China: a repeat cross-sectional study. BMJ Open 2016;6:e010058.

69 Mbulo L, Murty KS, Zhao L, et al. Tobacco use and secondhand smoke exposure among older adults in India. J Aging Health 2021;33:565-76.

70 Frazer K, Fitzpatrick P, Brosnan M, et al. Smoking prevalence and secondhand smoke exposure during pregnancy and postpartumestablishing risks to health and human rights before developing a tailored programme for smoking cessation. Int J Environ Res Public Health 2020;17:1. doi:10.3390/ijerph17061838

71 King BA, Homa DM, Dube SR, et al. Exposure to secondhand smoke and attitudes toward smoke-free workplaces among employed U.S. adults: findings from the National adult tobacco survey. Nicotine Tob Res 2014;16:1307-18.

72 Lee B-E, Ha E-H. Exposure to environmental tobacco smoke among South Korean adults: a cross-sectional study of the 2005 Korea National health and nutrition examination survey. Environmental Health 2011;10:1-10. 
73 Fischer F, Minnwegen M, Kaneider U, et al. Prevalence and determinants of secondhand smoke exposure among women in Bangladesh, 2011. Nicotine Tob Res 2015;17:58-65.

74 Bonevski B, Paul C, Jones A, et al. Smoky homes: gender, socioeconomic and housing disparities in second hand tobacco smoke (SHS) exposure in a large population-based Australian cohort. Prev Med 2014;60:95-101.

75 Fischer F, Kraemer A. Factors associated with secondhand smoke exposure in different settings: results from the German health update (GEDA) 2012. BMC Public Health 2016;16:1-9.

76 López MJ, Arechavala T, Continente X, et al. Social inequalities in secondhand smoke exposure in children in Spain. Tob Induc Dis 2018;16:1-6.

77 Akinboro O, Olorunfemi O, Basak P, et al. Secondhand smoke exposure among community-dwelling adult cancer survivors in the United States: 1999-2012. Cancer Epidemiol Biomarkers Prev 2017;26:1296-305.

$78 \mathrm{Nan} \mathrm{X}, \mathrm{Lu} \mathrm{H}, \mathrm{Wu}$ J, et al. Prevalence, knowledge and education level associated with secondhand smoke exposure among neversmoking women in inner Mongolia, Northern China. Tob Induc Dis 2020;18:1-11.

79 Vitória PD, Nunes C, Precioso J. Parents' educational level and second-hand tobacco smoke exposure at home in a sample of Portuguese children. Rev Port Pneumol 2017;23:221-4.

80 Gharaibeh H, Haddad L, Alzyoud S, et al. Knowledge, attitudes, and behavior in avoiding secondhand smoke exposure among nonsmoking employed women with higher education in Jordan. Int $J$ Environ Res Public Health 2011;8:4207-19.

81 TurkStat, Türkiye Sağlık Araștırması (turkey health survey) Yayın NO: 4590, 2020: Ankara.

82 Cavelaars AE, Kunst AE, Geurts JJ, et al. Educational differences in smoking: international comparison. BMJ 2000;320:1102-7.

83 Assari S, Mistry R. Educational attainment and smoking status in a national sample of American adults; evidence for the blacks' diminished return. Int J Environ Res Public Health 2018;15:763-12.

84 Karaaslan K.Ç. Determinants of online Shopping attitudes of households in turkey. J Model Manag 2021.

85 Karaaslan K.Ç. Analysis of factors affecting individuals' sources of Happiness with multinominal logistic model. J Measure Evaluat Educat Psychol 2021;12:286-302.
86 Crimmins EM, Saito Y. Trends in healthy life expectancy in the United States, 1970-1990: gender, racial, and educational differences. Soc Sci Med 2001;52:1629-41.

87 Alkan Ömer, Abar H, Gençer Özge. Analysis of factors affecting alcohol and tobacco concurrent use by bivariate probit model in turkey. Environ Sci Pollut Res Int 2021;28:1-8.

88 Alkan Ömer, Abar H. Determination of factors influencing tobacco consumption in Turkey using categorical data analyses. Arch Environ Occup Health 2020;75:27-35.

89 Alkan Ömer, Tekmanlı HH. Determination of the factors affecting sexual violence against women in Turkey: a population-based analysis. BMC Womens Health 2021;21:1-15.

90 Stafylis C, Rachiotis G, Katsioulis A, et al. Prevalence and determinants of smoking and secondhand smoke exposure in a rural population of central Greece: a cross-sectional study. Rural Remote Health 2018;18:4218.

91 Li Z, Yao Y, Yu Y, et al. Prevalence and associated factors of passive smoking among women in Jilin Province, China: a cross-sectional study. Int J Environ Res Public Health 2015;12:13970-80.

92 Schou AL, Mølbak M-L, Schnor P, et al. Alcohol consumption, smoking and development of visible age-related signs: a prospective cohort study. J Epidemiol Community Health 2017;71:1177-84.

93 Patten SB, Williams JVA, Lavorato DH, et al. Major depression and secondhand smoke exposure. J Affect Disord 2018;225:260-4.

94 Zeng Y-N, Li Y-M. Secondhand smoke exposure and mental health in adults: a meta-analysis of cross-sectional studies. Soc Psychiatry Psychiatr Epidemiol 2016;51:1339-48.

95 Alghamdi AS, Faisal Jokhadar H, Mohammed Alghamdi I, et al. Socioeconomic determinants of exposure to secondhand smoke among pregnant women. Int $J$ Women Health Reproduct Sci 2016;4:59-63.

96 Li Q, Hsia J, Yang G. Prevalence of smoking in China in 2010. N Engl J Med Overseas Ed 2011;364:2469-70.

97 Tanaka K, Miyake Y, Hanioka T, et al. Active and passive smoking and prevalence of periodontal disease in young Japanese women. $J$ Periodontal Res 2013;48:600-5.

98 Greaves LJ, Hemsing NJ. Sex, gender, and secondhand smoke policies: implications for disadvantaged women. Am J Prev Med 2009;37:S131-7. 